\title{
Relationship Between Sonic Hedgehog Protein, Brain-Derived Neurotrophic Factor and Oxidative Stress in Autism Spectrum Disorders
}

\author{
Laila Y. Al-Ayadhi
}

Received: 19 August 2011/Revised: 27 September 2011/Accepted: 29 September 2011/Published online: 9 October 2011

(C) The Author(s) 2011. This article is published with open access at Springerlink.com

\begin{abstract}
The etiology of autism spectrum disorders (ASD) is not well known but oxidative stress has been suggested to play a pathological role. We report here that the serum levels of Sonic hedgehog $(\mathrm{SHH})$ protein and brain-derived neurotrophic factor (BDNF) might be linked to oxidative stress in ASD. By using the whole blood or polymorphonuclear leukocytes, we demonstrated that autistic children produced a significantly higher level of oxygen free radicals (OFR). In addition, we found significantly higher levels of serum SHH protein in children with mild as well as severe form of autism. We also found that the serum level of BDNF was significantly reduced in autistic children with mild form of the disorder but not with severe form of the disorder. Our findings are the first to report a correlation between SHH, BDNF and OFR in autistic children, suggesting a pathological role of oxidative stress and SHH in autism spectrum disorders.
\end{abstract}

Keywords Autism spectrum disorders · Sonic hedgehog · BDNF · OFR

\section{Introduction}

Autism spectrum disorders (ASD) refer to a broad spectrum of neurodevelopmental disorders known as pervasive developmental disorders (PDD), including autism,

\footnotetext{
L. Y. Al-Ayadhi ( $\square)$

Department of Physiology, Autism Research \& Treatment Center (ART Center), AL-Amodi Autism Research Chair, Faculty of Medicine, King Saud University, P.O. Box 2925, Riyadh 11461, Saudi Arabia

e-mail: ayadh2@gmail.com
}

Asperger's syndrome, Rett's syndrome, and childhood disintegrative disorder. By definition, ASD are characterized by impairments in verbal and nonverbal communication and social interaction [1], with onset usually occurring around the first 36 months of childhood. Repetitive, stereotyped, purposeless behaviors as well as attention and sensory dysfunctions are common findings in patients with ASD. In recent years, the prevalence of ASD has increased dramatically, and this increase, cannot be attributed completely to improved diagnostic techniques and increased awareness only [2]. Latest reports estimate that ASD affects approximately one in every hundred children, with a male-to-female ratio of four to one (4:1) [2]. Despite that the fact that there is an increase in autism research worldwide, exact etiology of autism and ASD remains largely unknown.

It is well known that oxidative stress resulting from excess generation of reactive-oxygen species (ROS) is a major contributing factor in neurodegenerative diseases such as Parkinson's disease, Alzheimer's disease and ASD [3].

Sonic hedgehog (SHH) protein is a signaling protein from the Hedgehog family. When SHH binds to its receptor Patched-1 (PTCH1), PTCH1 cannot interact with the transmembrane protein Smoothened (SMO), resulting in activation of transcription factor GLI. The activated GLI regulates expression of many target genes that control cell growth, survival, and differentiation in a wide variety of cells, including neurons [4]. SHH signaling is vital during embryonic development. Previous studies have demonstrated that SHH signaling is activated in adult organism after injury and is involved in tissue repair mechanisms $[4,5]$.

Activation of SHH pathway up-regulates two neurotrophic factors, namely vascular endothelial growth factor (VEGF) and brain-derived neurotrophic factor (BDNF). As a result, activation of $\mathrm{SHH}$ signaling protects cortical 
neurons against oxidative stress that also led to the proposal of a potential role of SHH for the clinical treatments of brain ischemia and neurodegenerative disorders [6]. Thus the aim of the present study was to explore the relationship of SHH pathway, oxidative stress and BDNF in children with ASD.

\section{Materials and Methods}

Patients and Subjects

Forty-four children with ASD were recruited in the study (41 males and 3 females) ranging in age from 3 to 9 years and 40 age- and sex- matched healthy children (38 males and 2 females) served as the control group. The diagnosis of autism was made by child neurophysiologist, and pediatrician based on the criteria of autistic disorder as defined in the DSM-IV, CARS. Complete diagnostic work-ups including medical, neurological, psychiatric, and psychological evaluations were done for all of the subjects. All were in good physical health and were not taking any medications or nutrient supplements. Written consent was obtained from the parents of each subject, according to the guidelines of the ethical committee of King Khalid Hospital, King Saud University, Riyadh, Saudi Arabia.

\section{Blood Samples}

After an overnight fasting, blood samples $(10 \mathrm{ml})$ were collected from children in both groups in plain test tubes. Blood samples were centrifuged at 3,000 rpm to collect serum samples, which were stored frozen in a freezer at $-80^{\circ} \mathrm{C}$ until the time of analytical assays.

\section{SHH Assay}

Serum level of SHH was measured using a commercially available sandwich enzyme immunoassay (ELISA) kit from CUSABIO BIOTECH CO. Ltd (Wuhan, China).

\section{BDNF Assay}

Serum level of BDNF was measured using a commercially available sandwich enzyme immunoassay (ELISA) kit from Emax Immunoassay System (Promega Corp., Madison, Wisconsin).

\section{Blood PMNL Isolation}

Polymorphonuclear leukocytes (PMNL) were separated by using PMNL isolation medium (Robbins Scientific
Corporation, Sunnyvale, CA). Five to seven milliliter of heparinized blood was layered over $4 \mathrm{ml}$ of PMNL-Isolation Medium in a $15 \mathrm{ml}$ tube and then centrifuged at $400 \times g$ for $30 \mathrm{~min}$ at room temperature. The leukocyte-rich plasma was carefully removed with a Pasteur pipette and transferred to a $15 \mathrm{ml}$ conical centrifuge tube, filled with phosphate buffered saline (PBS) and centrifuged at $350 \times g$ for 10 min (Jouan centrifuge Model B4i, France). Two milliliter of lysing buffer $\left(0.87 \% \mathrm{NH}_{4} \mathrm{Cl}\right)$ were added to lyse residual erythrocytes and the cell suspension was, centrifuged at $250 \times g$ for $10 \mathrm{~min}$. The supernatant was discarded and the pellet was resuspended in $1 \mathrm{ml}$ of $5 \%$ fetal calf serum (FCS). A cell count taken that was then to a desired final concentration $[7,8]$. Cell viability was determined by trypan blue $(0.2 \%)$ exclusion method $[7,8]$.

Chemiluminescence Assay and Oxygen Free Radicals Measurement: Luminol-Enhanced Chemiluminescence

A Berthold (AutoLumatPlus LB 953) luminometer with a constant temperature $\left(37^{\circ} \mathrm{C}\right)$ controller (Bethold Technologies GmbH \& Co. KG, Calmbacher Stra $\beta$ e 22, D-75323 Bad Wildbad-Germany) connected to a computer was used. The reaction mixture consisted of $100 \mu \mathrm{l}$ of whole blood or PMNLs suspension and $900 \mu \mathrm{l}$ medium containing $10^{-5} \mathrm{M}$ luminol (5-amino-2,3-dihydro,1,4-phthalazinedione Sigma Chemical Co., St. Louis, MO, USA), $2 \mathrm{ng} / \mathrm{ml}$ phorbol myristate acetate (PMA) Sigma Chemical Co., St. Louis, MO, USA, $1.25 \mathrm{mg} / \mathrm{ml}$ opsonized zymosan (OPZ) Sigma Chemical Co., St. Louis, MO, USA and phosphate buffered saline (PBS). Whole blood or PMNLs suspension, triggered by adding prepared PMA or OPZ solution. Light emission was recorded in millivolts $(\mathrm{mV})$ and the readings were recorded at $1 \mathrm{~min}$ intervals for $30 \mathrm{~min}$. CL emission was quantified as the peak height in $\mathrm{mV}[7,8]$.

Statistical Analysis

Metabolic data are presented as means \pm standard deviation (SD). Statistical differences were ascertained by using the Student's $t$ test with significance set at a $P$ value of 0.05 or lower.

\section{Results}

The results of the respiratory burst of whole blood and PMNLs from autistic and control subjects are shown in Tables 1, 2, 3 and 4. The respiratory burst of whole blood stimulated with PMA and OPZ, autistic (males and females) were significantly higher $(P<0.05)$ compared to control children (Tables 1 and 2). This increase was not related to the severity of the disorder. Similar findings were 
Table 1 Respiratory burst of whole blood stimulated by PMA, as measured by chemiluminescence (CL), in control and children with ASD

\begin{tabular}{llrl}
\hline Subjects participated $(\mathrm{n}=$ no. of subjects) & \multicolumn{2}{l}{ CL measurement $(\mathrm{mV})$} & \\
\cline { 2 - 4 } & Basal & Maximum peak $(\mathrm{mV})$ & Time to peak (min) \\
\hline Control & & & $10 \pm 4$ \\
Male $(\mathrm{n}=38)$ & $0.90 \pm 0.6$ & $12 \pm 6$ & $1,800 \pm 53$ \\
Female $(\mathrm{n}=2)$ & $0.92 \pm 0.7$ & & $1,721 \pm 65$ \\
Autistic & & $24.13 \pm 2^{*}$ & $1,960 \pm 70$ \\
Male $(\mathrm{n}=41)$ & $1.81 \pm 0.5$ & $23.7 \pm 6^{*}$ & $1,720 \pm 21$ \\
Female $(\mathrm{n}=3)$ & $1.5 \pm 0.3$ & \\
\hline
\end{tabular}

PMA concentration $=2 \mu \mathrm{g} /$ cuvete; Luminol concentration $=2 \mathrm{M}^{4} /$ cuvete; Values are expressed as mean $\pm \mathrm{SD}$

* $P<0.05$ (as compared to control group)

Table 2 Respiratory burst of whole blood stimulated by OPZ, as measured by chemiluminescence (CL), in control and children with ASD

\begin{tabular}{|c|c|c|c|}
\hline \multirow[t]{2}{*}{ Subjects participated $(\mathrm{n}=$ no. of subjects) } & \multicolumn{3}{|c|}{ CL measurement $(\mathrm{mV})$} \\
\hline & Basal & Maximum peak (mV) & Time to peak (min) \\
\hline \multicolumn{4}{|l|}{ Control } \\
\hline Male $(\mathrm{n}=38)$ & $0.90 \pm 0.6$ & $10 \pm 4$ & $2,216 \pm 65$ \\
\hline Female $(\mathrm{n}=2)$ & $0.92 \pm 0.7$ & $12 \pm 6$ & $2,310 \pm 54$ \\
\hline \multicolumn{4}{|l|}{ Autistic } \\
\hline Male $(n=41)$ & $1.81 \pm 0.5$ & $24.13 \pm 2 *$ & $3,258 \pm 76$ \\
\hline Female $(\mathrm{n}=3)$ & $1.5 \pm 0.3$ & $23.7 \pm 6^{*}$ & $3,174 \pm 62$ \\
\hline
\end{tabular}

$\mathrm{OPZ}$ concentration $=200 \mu \mathrm{g} / \mathrm{ml}$; Luminol concentration $=2 \mathrm{M}^{4} /$ cuvete; Values are expressed as mean $\pm \mathrm{SD}$

$* P<0.05$ (as compared to control group)

Table 3 Respiratory burst of polymorphoneuclear leukocytes (PMNLs), stimulated by PMA, as measured by chemiluminescence (CL) in control and children with ASD

\begin{tabular}{|c|c|c|c|}
\hline \multirow[t]{2}{*}{ Subjects participated $(\mathrm{n}=$ no. of subjects) } & \multicolumn{3}{|c|}{ CL measurement $(\mathrm{mV})$} \\
\hline & Basal & Maximum peak (mV) & Time to peak (min) \\
\hline \multicolumn{4}{|l|}{ Control } \\
\hline Male $(\mathrm{n}=38)$ & $17.32 \pm 6$ & $303 \pm 34$ & $728 \pm 35$ \\
\hline Female $(\mathrm{n}=2)$ & $18.43 \pm 1.5$ & $298 \pm 26$ & $875 \pm 42$ \\
\hline \multicolumn{4}{|l|}{ Autistic } \\
\hline Male $(\mathrm{n}=41)$ & $31.8 \pm 3$ & $378 \pm 51^{*}$ & $593 \pm 54$ \\
\hline Female $(\mathrm{n}=3)$ & $29.7 \pm 4$ & $412 \pm 41^{*}$ & $643 \pm 75$ \\
\hline
\end{tabular}

PMA concentration $=2 \mu \mathrm{g} /$ cuvete; Luminol concentration $=2 \mathrm{M}^{4} /$ cuvete; Values are expressed as mean $\pm \mathrm{SD}$

$* P<0.05$ (as compared to control group)

also found in the respiratory burst of PMNLs from autistic and control children (Tables 3 and 4) and the increase was not related to the severity of the disorder.

Furthermore, BDNF serum level were significantly higher in mild autistic children compared to age and sex matched control subjects (442 \pm 20 (pg.ml), $290 \pm 90$ (pg/ml), $P<0.05$ ), respectively. On the other hand, serum level of BDNF, was not statistically significant in severe autism as compared to age and sex matched control/subjects $(323 \pm 114(\mathrm{pg} / \mathrm{ml}), 290 \pm 90(\mathrm{pg} / \mathrm{ml}), P>0.05)$ respectively, Fig. 1. In addition, Sonic hedgehog serum level were very highly statistically significant in mild $(10.4 \pm 3(\mathrm{pg} / \mathrm{ml}))$ and severe autism $(24.2 \pm 6(\mathrm{pg} / \mathrm{ml}))$ compared to control $(2.6 \pm 2(\mathrm{pg} / \mathrm{ml})) P<0.0001)$, Fig. 2 . In addition, the level of $\mathrm{SHH}$ were positively correlated with the severity of autism $(r=0.69)$ Fig. 3 . 
Table 4 Respiratory burst of polymorphoneuclear leukocytes (PMNLs), stimulated by OPZ, as measured by chemiluminescence (CL) in control and children with ASD

\begin{tabular}{llll}
\hline Subjects participated $(\mathrm{n}=$ no. of subjects) & \multicolumn{2}{l}{ CL measurement $(\mathrm{mV})$} & \\
\cline { 3 - 4 } & Basal & Maximum peak $(\mathrm{mV})$ & Time to peak (min) \\
\hline Control & & & $303 \pm 34$ \\
$\quad$ Male (28) & $17.32 \pm 6$ & $298 \pm 26$ & $2,206 \pm 45$ \\
Female (18) & $18.43 \pm 1.5$ & & $2,234 \pm 54$ \\
Autistic & & $378 \pm 51^{*}$ & $1,713 \pm 64$ \\
Male (35) & $31.8 \pm 3$ & $412 \pm 41^{*}$ & $1,905 \pm 54$ \\
Female (5) & $29.7 \pm 4$ & \\
\hline
\end{tabular}

$\mathrm{OPZ}$ concentration $=200 \mu \mathrm{g} / \mathrm{ml}$; Luminol concentration $=2 \mathrm{M}^{4} /$ cuvete; Values are expressed as mean $\pm \mathrm{SD}$

$* P<0.05$ (as compared to control group)

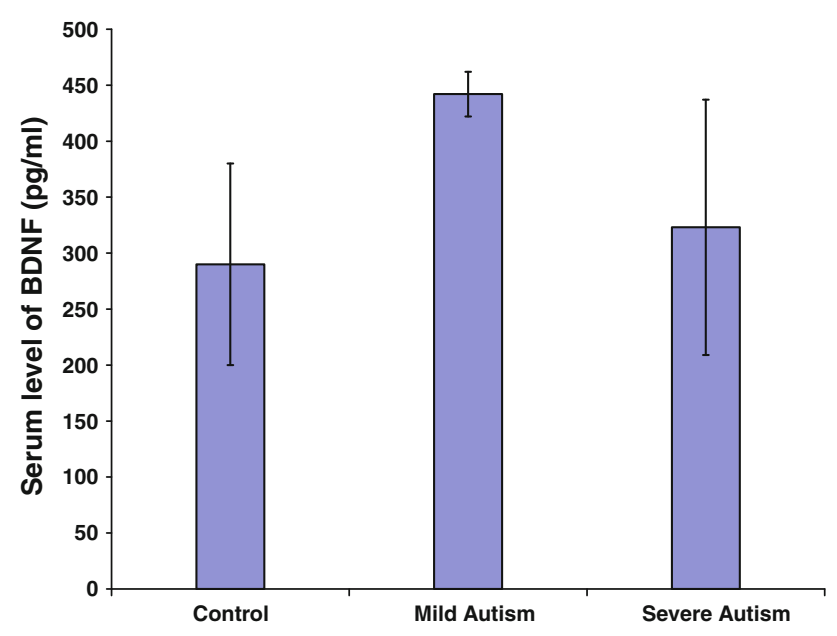

Fig. 1 Serum levels of BDNF in control and autistic children. BDNF in mild and severe ASD, compared to control subject. BDNF serum level were significantly high in mild but not severe autistic children compared to age and sex matched subjects $442 \pm 20(\mathrm{pg} / \mathrm{ml})$, $290 \pm 90(\mathrm{pg} / \mathrm{ml}), P<0.05)$, respectively



Fig. 2 Serum levels of Sonic hedgehog protein in control and autistic children. Highly statistically significant Sonic hedgehog serum level in mild and severe autism



Fig. 3 Relationship between SHH serum level and CARS score. Serum Level of SHH protein was positively correlated with the severity of autism $(r=0.69)$

\section{Discussion}

The etiology of ASD is not well understood, though it likely involves genetic, immunologic, and environmental factors [9]. The dramatic increase in reported prevalence has encouraged an intense effort to identify early biological markers [10]. Such markers could allow for earlier identification and therapeutic intervention, contributing to improved prognosis [11]. In the current study, we speculated an important connection between SHH, BDNF pathways and oxidative stress. In our study, we demonstrated statistically significant increase in free radicals production (superoxide anion $(\mathrm{O} 2)$ hydrogen peroxide $(\mathrm{H} 2 \mathrm{O} 2)$, and hydroxyl radicals $(\mathrm{OH})$ ), from whole blood and isolated human PMNLs in autistic children when compared to age and sex matched control. This increase was not related to the degree of autism, or to the age of affected child. In 
addition, we demonstrated higher serum level of SHH concentration, which was positively correlated with the degree of autism. Furthermore, we found a statistically significant higher level of BDNF in mild but not in sever autism.

Oxidative stress is a process caused by exposure to reactive oxygen intermediates, such as superoxide anion $\left(\mathrm{O}_{2}{ }^{-}\right)$hydrogen peroxide $\left(\mathrm{H}_{2} \mathrm{O}_{2}\right)$, hydroxyl radicals $(\mathrm{OH})$ and nitric oxide (NO) which can damage proteins, nucleic acids and cell membranes. The ROS within the cells are neutralized by antioxidant defense mechanisms. SOD, catalase and glutathione peroxidase (GPx) are the primary enzymes involved in direct elimination of ROS, whereas glutathione reductase and glucose-6-phosphate dehydrogenase are secondary antioxidant enzymes, which help in maintaining a steady concentration of glutathione and NADPH necessary for optimal functioning of the primary antioxidant enzymes [12-15]. Under normal conditions, a dynamic equilibrium exists between the production of reactive oxygen species (ROS) and the antioxidant capacity of the cell $[16,17]$. In pathological conditions, over production of OFR or less effective antioxidant enzymatic system, takes place, resulting in OFR overflow which leads to tissue damage. Oxidative stress is an important mechanism involved in brain damages, as consequences of exposure to reactive oxygen species (ROS) [15, 17].

Brain-derived neurotrophic factor (BDNF) is a small protein found throughout the central nervous system (CNS) and peripheral blood. BDNF is the most widely distributed neurotrophin in the CNS. BDNF plays a critical role in axonal and dendritic growth and guidance. In addition, BDNF participates in neurotransmitter release [18]. BDNF is involved in the survival and differentiation of dopaminergic neurons in the developing brain $[18,19]$ and plays an important role in the formation and plasticity of synaptic connections [20].

Within the nervous system, SHH protein is associated with development and patterning of the central nervous system [5, 21, 22]. Latest reports have signified a critical role played by SHH pathway in many neurological diseases. However, its exact role and the underlying mechanisms are still unclear. It has been reported that SHH expression is up-regulated prior to the induction of BDNF mRNA, and blocking SHH signals suppresses BDNF expression [23]. Considering the protective role of BDNF against oxidative stress [24], therefore, activation of the SHH pathway induces the increase of BDNF and results in neuroprotective to oxidative stress. BDNF belongs to the neurotrophin family that may affect neuronal survival and differentiation. SHH is a morphogen important for the embryonic development. Possible correlation between BDNF and SHH is less well studied. Hashimoto and his colleagues in 2008, demonstrated up-regulation of SHH expression, prior to the induction of BDNF mRNA in Schwann cells adjacent to the injured site in an animal model of sciatic nerve injury [23]. The same research group demonstrated causative relationship between the induction of SHH and BDNF, continuous administration of hedgehog inhibitor CPM to the injured site suppressed the increase of BDNF expression and, notably, deteriorated the survival of motor neurons in lumbar spinal cord [23].

$\mathrm{Wu}$ et. al. [25], demonstrated BDNF-induced up-regulation of SHH at both mRNA and protein levels, suggestive of involvement of a transcriptional mechanism. Furthermore, the protective effect of BDNF was abolished by SHH signaling inhibitor CPM. In addition, exogenous SHH-N alone mimicked BDNF action that was sufficient to attenuate 3-NP toxicity towards cortical neurons in a dose- and time-dependent fashion [25]. Lately, a protective action exerted by SHH has been revealed in several animal models of ischemia/reperfusion [26]. In addition, pretreatment of SHH has been shown to protect cardiomyocytes against hydrogen peroxide-induced cytotoxicity in vitro [27]. As a result, SHH may offer both anti oxidative and anti-apoptotic actions under appropriate circumstances. Metabolic stress induced by compromised mitochondria has been implicated in both acute and chronic neurodegenerative disorders such as ischemic stroke, Alzheimer's disease, Parkinson's disease (PD), and HD. It has also been shown that SHH reduces behavioral deficits induced by intrastriatal 6 hydroxydopamine (6-OHDA) lesion and suggests that SHH may be useful in the treatment of disorders that affect the nigrostriatal system, such as PD [28].

Systemic administration of several neurotrophins such as nerve growth factors and brain derived growth factor can attenuate neuronal damage induced by chemical hypoxia in vivo by a mechanism which may involve attenuation of oxidative stress in neonatal rat model [29].

Normal SHH pathway was found to be necessary for wound healing, and impaired coetaneous SHH signaling pathway contributes to impaired NO function and wound healing in diabetes. Delivery of exogenous SHH protein or its receptor agonists may provide an effective means in accelerating diabetic wound healing. Strategies aimed at augmenting endogenous SHH pathway may provide an effective means in ameliorating delayed diabetic wound healing [30].

An increase in SHH protein was initially reported in the gray matter from multiple sclerosis brains lesions [31] or in animal models of this pathology including Experimental Autoimmune Encepalomyelitis and cuprizone-induced demyelination [32, 33]. The clinical improvement and reduced demyelination driven by either interferon-b or triiodothyronine in several rodent models of demyelinating diseases are likely linked to an enhanced expression of SHH $[32,33]$. It points out towards a possible protective 
effect of exerted by $\mathrm{SHH}$ and it is with agreement to our findings in autism. The most likely explanation for higher level of SHH in autistic examined in this study is as a result of increased oxygen free radicals production as a protective mechanism secondary to increase oxidative stress inside the autistic. The roles of the SHH signaling pathway in the CNS are gaining some interest lately, due to a multifunctional properties of $\mathrm{SHH}$, ranging from the regulation of new cells production to the modulation of neuronal electrophysiological activity. The higher levels of OFR and consequently SHH, demonstrated in the current study, in mild ASD, resulted in an increase BDNF production as a protective mechanism. In severe ASD the further increase in OFR and $\mathrm{SHH}$, produced a negative feed back response on the production of BDNF, as demonstrated by lower level of BDNF in severe but not in mild ASD. Existing data provide support for considering $\mathrm{SHH}$ signaling as an important mechanism in tissue-repair process in brain diseases, and as a target for novel therapeutic approaches for the treatment of brain disorders and in particular ASD.

\section{Conclusion}

The present study demonstrated the possible critical protective role played by SHH and BDNF in ASD, particularly in relation to oxidative stress. Larger studies are strongly recommended, to investigate the significant role played by BDNF in ASD phenotypes. Explanation of the underlying molecular mechanism may help develop a novel therapeutic intervention for neuronal protection in ASD.

\begin{abstract}
Acknowledgments The author wishes to thank all children and parents who participated in the study. Without them it was not possible to conduct the study. Special thanks to King Abdul Aziz City for Science and Technology (KACST); and Al-amodi autism research chair for funding the project.
\end{abstract}

Open Access This article is distributed under the terms of the Creative Commons Attribution Noncommercial License which permits any noncommercial use, distribution, and reproduction in any medium, provided the original author(s) and source are credited.

\section{References}

1. Trottier G, Srivastava L, Walker CD (1999) Etiology of infantile autism. A review of recent advances in genetic and neurological research. J Psychiatry Neurosci 24:103-115

2. American Psychiatric Association. (2000) American psychiatric association, diagnostic and statistical manual-text revision (DSMIV-TR TM). American Psychiatric Association, Washington, DC

3. Chauhan A, Chauhan V (2006) Oxidative stress in autism. Pathophysiol Oxidative Stress Metab Dis 13(3):171-181

4. Hooper JE, Scott MP (2005) Communicating with hedgehogs. Nat Rev Mol Cell Biol 6:306-317
5. Riobo NA, Manning DR (2007) Pathways of signal transduction employed by vertebrate Hedgehogs. Biochem J 403:369-379

6. Dai R-L, Zhu S-Y, Xia Y-P, Mao L, Mei Y-W, Yao Y-F, Xue Y-M, Hu B (2011) Sonic hedgehog protects cortical neurons against oxidative stress. Neurochem Res 36:67-75

7. AL-Ayadhi L (2004) The effect of adrenomedullin on oxygen free radicals production and aggregation of isolated human polymorphoneuclear leukocyte. Saudi Pharm J 12(2-3):80-85

8. Al-Tuwaijri AS, Mustafa AA (1992) Verapamil enhances the inhibitory effects of diclofenac on the chemiluminescence response of human polymorphonuclear leukocytes and carrageenan-induced rat's paw oedema. Int J Immunopharmac 14(1):83-91

9. Volkmar FR, Lord C, Bailey A, Schultz RT, Klin A (2004) Autism and pervasive developmental disorders. J Child Psychol Psychiatr 45(1):135-170

10. Chakrabarti S, Fombonne E (2005) Pervasive developmental disorders in preschool children: confirmation of high prevalence. Am J Psychiatr 162:1133-1141

11. Aman MG (2005) Treatment planning for patients with autism spectrum disorders. J Clin Psychiatr 66(Suppl 10):38-45

12. Gutterridge JMC, Richmond R, Halliwell B (1980) Oxygen freeradicals and lipid peroxidation. Inhibition by the protein ceruloplasmin. FEBS Lett. 112:269-272

13. Vendemiale G, Grattagliano I, Altomare E (1999) An update on the role of free radicals and antioxidant defense in human disease. J. Clin Lab Res 29:49-55

14. Halliwell B, Gutteridge JMC (1992) Role of free radicals and catalytic metal ions in human disease and an overview. Brain Inj 6:203-212

15. Loeffler DA, Connor JR, Juneau PL, Snyder BS, Kanaley L, DeMaggio AJ, Nguyen H, Brickman CM, LeWitt PA (1995) Transferrin and iron in normal, Alzheimer's disease, and Parkinson's disease brain regions. J Neurochem 65:710-724

16. Kannan K, Jain SK (2000) Oxidative stress and apoptosis. Pathophysiology 7:153-163

17. AL-Ayadhi L (2009) Increased oxygen free radical production from isolated human PMNLs and whole blood by luminolenhanced chemiluminescence in autistic children. Kuwait Med J 41(1):26-30

18. Hyman C, Hofer M, Barde YA, Juhasz M, Yancopoulos GD, Squinto SP, Lindsay RM (1991) BDNF is a neurotrophic factor for dopaminergic neurons of the substantia nigra. Nature 350:230-232

19. Teixeira A, Guimaraes BI, Diniz B, Kummer A (2010) Circulating level of brain-derivied neurotrophic factor: correlation with mood, cognition and motor function. Biomarkers Med 4(6):871-887

20. Binder DK, Scharfman HE (2004) Brain-derived neurotrophic factor. Growth Factors 22:123-131

21. Banerjee SB, Rajendran R (2005) Recruitment of the sonic hedgehog signalling cascade in electroconvulsive seizure-mediated regulation of adult rat hippocampal neurogenesis. Eur $\mathrm{J}$ Neurosci 22:1570-1580

22. Hurtado-Lorenzo A, Millan E, Gonzalez-Nicolini V, Suwelack D, Castro MG, Lowenstein PR (2004) Differentiation and transcription factor gene therapy in experimental Parkinson's disease: sonic hedgehog and Gli-1, but not Nurr-1, protect nigrostriatal cell bodies from 6 OHDA induced neurodegeneration. Mol Ther 10(3):507-524

23. Hashimoto M, Ishii K, Nakamura Y, Watabe K, Kohsaka S, Akazawa C (2008) Neuroprotective effect of sonic hedgehog upregulated in Schwann cells following sciatic nerve injury. J Neurochem 107:918-927

24. Ebadi M, Srinivasan SK, Baxi MD (1996) Oxidative stress and antioxidant therapy in Parkinson's disease. Prog Neurobiol 48(1):1-19 
25. Wu CL, Chen SD, Hwang CS, Yang DI (2009) Sonic hedgehog mediates BDNF-induced neuroprotection against mitochondrial inhibitor 3-nitropropionic acid. Biochem Biophys Res Commun 385(1):112-117

26. Pola R, Ling LE, Silver M, Corbley MJ, Kearney M, Pepinsky RB, Shapiro R, Taylor FR, Baker DP, Asahara T, Isner JM (2001) The morphogen sonic hedgehog is an indirect angiogenic agent upregulating two families of angiogenic growth factors. Nat Med 7:706-711

27. Tsuboi K, Shults CW (2002) Intrastriatal injection of sonic hedgehog reduces behavioral impairment in a rat model of Parkinson's disease. Exp Neurol 173:95-104

28. Kirschner PB, Jenkins BG, Schulz JB, Finkelstein SP, Matthews RT, Rosen BR, Flint Beal M (1996) NGF, BDNF and NT-5, but not NT-3 protect against $\mathrm{MPP}^{+}$toxicity and oxidative stress in neonatal animals. Brain Res 713:178-185

29. Luo JD, Hu TP, Wang L, Chen MS, Liu SM, Chen AF (2009) Sonic hedgehog improves delayed wound healing via enhancing cutaneous nitric oxide function in diabetes. Am J Physiol Endocrinol Metab 297:525-531
30. Wang Y, Imitola J, Rasmussen S, O'Connor KC, Khoury SJ (2008) Paradoxical dysregulation of the neural stem cell pathway sonic hedgehog-Gli1 in autoimmune encephalomyelitis and multiple sclerosis. Ann Neurol 64(4):417-427

31. Seifert T, Bauer J, Weissert R, Fazekas F, Storch MK (2005) Differential expression of sonic hedgehog immunoreactivity during lesion evolution in autoimmune encephalomyelitis. J Neuropathol Exp Neurol 64(5):404-411

32. Mastronardi FG, daCruz LA, Wang H, Boggs J, Moscarello MA (2003) The amount of sonic hedgehog in multiple sclerosis white matter is decreased and cleavage to the signaling peptide is deficient. Mult Scler 9(4):362-371

33. Harsan LA, Steibel J, Zaremba A, Agin A, Sapin R, Poulet P, Guignard B, Parizel N, Grucker D, Boehm N, Miller RH, Ghandour. MS (2008) Recovery from chronic demyelination by thyroid hormone therapy: myelinogenesis induction and assessment by diffusion tensor magnetic resonance imaging. J Neurosci 28(52):14189-14201 